\title{
Teacher Professional Development in Hong Kong Compared to Anglosphere: the Role of Confucian Philosophy
}

\author{
LAM Bick Har \\ The Hong Kong Institute of Education (Hong Kong) \\ (Received on January 20, 2015; Accepted on April 4, 2015)
}

\begin{abstract}
Teacher Professional Development" (aka teacher PD) has garnered research attention in recent years. Scholars seek to understand the teacher PD process, while practitioners are interested in deriving policies to facilitate teacher PD. The consensus emerging from the pool of literature is that teacher PD should be "individualized": more focused on fostering teachers' personal growth instead of enforcing "standard practices". The Anglosphere has been leading in the domain of teacher PD, causing many regions to imitate its practices. Using documentary analysis, this paper reviews teacher PD policies in Hong Kong over the past forty years and compares them with practices typically adopted in the Anglosphere. The paper suggests that the PD policies of Hong Kong progressed from 'solely teacher training', to 'emphasis on generic skills', to 'lifelong learning'. The concept of 'Confucian Heritage Culture' is used to explain the differences between the Angloshpere and Hong Kong in terms of PD practices. Implications for adapting teacher PD practices cross-culturally are discussed.
\end{abstract}

Keywords: culture, education policies, Hong Kong, teacher professional development

Correspondence: LAM Bick Har. Associate Professor. Room 32, Department of Curriculum and Instruction, Hong Kong Institute of Education, 10 Lo Ping Road, Tai Po, New Territories (Hong Kong). Email: bhlam@ied.edu.hk

\section{How to cite this article?}

Lam, B. H. (2015). Teacher professional development in Hong Kong compared to anglosphere: the role of Confucian philosophy. Psychology, Society and Education, 7(3), 295-310. 


\section{Introduction}

"Professional Development" has been a widely researched phenomenon in social science (e.g., Guskey, 2002; Speck \& Knipe, 2005). The term was at first coined by scholars from organizational behaviors to refer to an individual's acquisition of skills and knowledge he/she needs to advance in his/her career (Speck \& Knipe, 2005), and is applied to study employees of various occupations, including nurse managers (Neary, 2000), scientists (Hunter, Laursen \& Seymour, 2007) and teachers (Guskey, 2002). Studies of teacher professional development in particular have drawn scholarly attention from educators - in education, a domain has formed on "Teacher Professional Development" (aka "Teacher Development" or "Teacher PD"). Teacher PD is now defined as processes through which a teacher acquires the skills and knowledge he/she needs to advance in his/her career (Guskey, 2002), and has a set of theories of its own. We know that teacher PD is linked to various teacher job outcomes: studies found that advancement in one's career is positively related to job commitment (Day \& Gu, 2007), and well-developed teachers tend to have students who achieve higher academically (Caprara, Barbaranelli, Steca \& Malone, 2006).

Meanwhile, the Hong Kong education system suffers from two problems: local school teachers responded that they bear high amounts of stress, which harms their job commitment (Choi \& Tang, 2009); moreover, although Hong Kong has had above-average scores in international tests, the falling standards of its students' proficiency in languages and other disciplines has been a regular complaint of local educators (Chan, 2002). As a result, teacher PD research has attracted attention among educators in Hong Kong (Chan, 1998; Lam, 2014). This article will serve to (1) review the trends of teacher PD in the 'Anglosphere' (the English-speaking world, including the United States, Australia, Canada, New Zealand, and the United Kingdom); (2) compare them with the practices of Hong Kong; and (3) draw insights from which other regions could learn. By comparing teacher PD in Hong Kong to what is being done in the Anglosphere, we will highlight key features of teacher PD in Hong Kong. We will also point out issues specific to the culture of CHCs. Via this, we will identify problems in adapting Anglosphere's practices to other cultures, and discuss possible solutions.

\section{The New Trend of Teacher PD in the Anglosphere}

A large number of studies have been conducted on teacher PD, each focusing on certain aspects (Avalos, 2011). All of them, however, had undergone a paradigm shift, in that teacher PD is increasingly seen as a long-term process which involves growth and development, rather than only pre- or in-service training programmes (Walling \& Lewis, 2000). Within this model, teachers are seen as active learners and reflective practitioners who are motivated to collaborate to learn (Darling-Hammond \& Richardson, 2009), and teachers' learning is contextualized, instead of revolving around a set of standard 'measures' to be applied to every single case (McLaughlin \& Zarrow, 2001) - an approach to teacher PD that is more catering to the individual, to be precise.

This trend has led to changes in teacher PD research and practices. In the past, 
research and practices often emphasized 'Teacher PD as acquiring knowledge' (Shulman, 1986; 1987). Thiessen (2000), for instance, stated that "At the heart of this orientation is the image of teaching as knowledge work. Such work [...] involves the interrelated use of practical knowledge (routines, procedures, processes) and propositional knowledge (discipline-based theories and concepts, pedagogical principles, situation-specific propositions)" (p. 528). As a result, early practices of teacher PD (before the 1980s) were heavy with training workshops and programmes (Ben-Peretz, 2011). There were also discussions of extending the length and depth of initial teacher education training in the English-speaking world (e.g., Cobb, 1999).

Later teacher PD (from the 1990s onwards), in contrast, became more inclined to emphasize how teachers can continually enhance their teaching based on their experience. Common practices include action research (Ross \& Bruce, 2007), where teachers are prompted to do small-scale studies that evaluate the effectiveness of their own teaching practices, rather than applying the standardized practices they learn during teacher training courses. This new model also has a 'collaborative' element, in that it brought about the practice of mentorship (Hagger, McIntyre, \& Wilkin, 2013), a process of relationship-based communication in which a 'mentor' transmits knowledge and gives psychological support to a 'mentee'. Research that evaluates the outcomes of teacher PD suggests that the new practices, including self-reflection (McKernan \& McKernan, 2013), action research (Stringer, 2007), and mentorship (Hagger et al., 2013) have been successful in fostering higher levels of job commitment and performance among teachers. As examples, Bustingorry (2008) examined a group of Chilean teachers who received action research training and found that the training enhanced the grades of students taught by those teachers. Hagger and colleagues' (2013) review on mentorship practices also indicated that the practice is generally helpful in enhancing teachers' performance. Overall, this body of new practices for teacher PD has been successful. As a result, many regions (including Hong Kong) are now adapting them to fit their needs with regard to teacher PD.

\section{Teacher PD in Hong Kong}

Policy documents published by the Hong Kong government in the past 40 years were the primary focus of the current article. Relevant texts were identified via the official websites of (1) the Education Bureau; (2) the Education Commission; and (3) the Committee on Professional Development of Principals and Teacher (aka COTAP, formerly the Advisory Committee on teacher Education and Qualifications, ACTEQ). We also consider the survey results that the Hong Kong Government obtained in 2006 and 2009, when evaluating the effectiveness of PD in Hong Kong. Even though the results of the two surveys could not be systematically compared with each other because the formats of the surveys were different, these results offer insights about the context of teacher PD in Hong Kong. All these documents and the statements of purposes of these three government bodies were included within the scope of the current review. 


\section{The trajectory of teacher PD in Hong Kong}

Our review of Hong Kong's teacher PD in the last four decades revealed that Hong Kong has followed a similar trajectory as the Anglosphere. In the early years (the 1980s and before), the Hong Kong government treated teacher PD as 'teacher training'. The training courses of local institutions were the sole teacher PD practices. Teachers were viewed as workers to be trained, as explicitly stated in a White Paper produced by the Hong Kong Government in 1978: "account must also be taken of other objectives, in particular ensuring a regular supply of trained teachers to meet teaching vacancies as they arise and providing basic training for untrained serving teachers" (p. 13). In the mid-1980s, the Hong Kong Education System (including the parts on teacher PD) was criticized by the Visiting Panel (1982), who conducted a series of observations in Hong Kong schools. One major point raised by the panel was that Hong Kong education was almost fully teacher-centered, and placed excessive emphasis on 'quantity' (training more teachers and producing more students) over 'quality' (providing high-quality education).

In response, the Hong Kong Government began to implement new policies to promote quality education in the 1990s. Educational interventions that focused not on students' grades, but on their non-academic development, became a part of the official policy for the first time (Educational and Manpower Branch, 1993). To cater to this, teacher PD also became geared towards equipping teachers with generic skills (Education Commission, 2000). Teachers were required to develop skills in counseling, information technology and languages, finished with examinations in which they were assessed on these competencies. Resources centers were set up to provide teachers with exemplary teaching materials. These paved a way for the shift to a more advanced teacher PD approach; as Education Commission (2000) stated, the new measures in the 2000 s would serve "to promote the professional development of teachers and enhance their professionalism, sense of commitment and enthusiasm" (p. 151). Thus, into the 2000s, the new paradigm of teacher PD gained momentum.

\section{Hong Kong teacher PD beyond year 2000}

The Education Bureau of Hong Kong has put forth the teacher Induction Scheme from 2005 onward (Education Bureau, 2014a). It is targeted at first-year post-qualification teachers, who are expected to be "provided with encouragement and support so that they enjoy positive learning experiences and a pleasant start to their careers", by their schools and seniors, via activities with "an element of self-reflection", instruments that serve to "document each beginning teacher's path of development", evaluations that "inform the future development of schools' induction systems", and the mentorship programmes (p. 2, Education Bureau, 2014a). This scheme did not officially dictate a set of procedures, but instead advised the use of techniques proposed by the ACTEQ (2009a). The ACTEQ's guidelines included specific actions which schools could engage in to induct their beginning teachers and have been empirically demonstrated to be helpful.

Another key theme of teacher PD practices in Hong Kong is the establishment 
of social networks among teachers. Collaborative Lesson Planning (Education Bureau, 2012), for example, prompts teachers to engage in scheduled meetings where they collaboratively plan their lessons and do sharing and reflections on teaching, with the goal of fostering exchanges of ideas among teachers, hence achieving teacher PD. The Education Bureau has also added sharing sessions both within and outside schools (2010) - each year, teachers from multiple schools will present sharing sessions on specific themes to inform fellow teachers about their own practices. To strengthen the networks even further, the Education Bureau also provided exchange programmes, in which Hong Kong school teachers were sent to teach in schools in Mainland China and Taiwan to learn about the education systems and techniques of these regions (e.g., Education Bureau, 2014b).

The practices related to the above two themes have been received favorably. According to ACTEQ's 2006 survey, about $80 \%$ of the teachers in Hong Kong responded that the above practices had been implemented in their schools, and more than $80 \%$ of them replied that they considered these practices to be helpful. More than $90 \%$ of the respondents replied that they believed the practices to have helped them (1) enhance their own teaching competence; (2) improve the effectiveness of learning and teaching; (3) enhance their understanding of subject matter knowledge; and (4) enhance their capacity for dealing with students' diverse learning needs. Therefore, these practices are an overall success.

Training aligned with these two themes were also provided to Hong Kong teachers. For instance, workshops that train teachers in mentorship are included in the teacher Induction Scheme (Education Bureau, 2014a). Specialized courses about leadership have also been provided to teachers since early 2000s (Hong Kong Institute of Education, 2014). The tradition of working to enhance teachers' qualifications is ongoing. For example, from the 2000 onward, teachers are required to obtain recognized certificates before they can be appointed in schools (Education Bureau, 2014c). Back in the 1990s, many teachers were unqualified but were allowed to teach due to shortage. By contrast, now over $95 \%$ of primary and secondary school teachers of Hong Kong fulfill the qualification requirement (Education Bureau, 2014d).

\section{Contrasting Hong Kong Practices with the Anglosphere}

The main teacher PD practices put forward by the Education Bureau are summarized in Annex 1. Overall, the teacher PD practices in Hong Kong resemble but also differ from those in the Anglosphere in many ways. Much as in the Anglosphere, teacher PD in Hong Kong began as 'merely training', but once the criticism against the approach arose, the government responded by implementing teacher PD practices that emphasized long-term growth and development for teachers. To accomplish this goal, Hong Kong worked to create cooperative ties between schools and universities (Wise, 2000), who served as the providers of professional development programmes and workshops. Training content is similar to the Anglosphere. Hong Kong also extensively used collaborative learning along with mentorship, two approaches commonly adopted by the Anglosphere (Sandholtz, 2000). 
Overall, teacher PD practices of Hong Kong resemble those in the dominant literature, with one critical difference: the lack of self-direction in Hong Kong. Although the majority of the common practices in the literature (as shown above) had been adapted into Hong Kong to some degree, practices with the element of 'self-direction' in development are noticeably missing. Glatthorn (1987), for example, described the idea of 'collegial development', where teachers are to discuss professional issues with personal interests (i.e., how they themselves, as individuals, should develop) with each other, to form individual professional development plans. Clarke (1995) later proposed the model about reflective practitioners, in which teachers are expected to be curious about the practice setting. Emerging from these, a recurrent theme of later teacher PD methods is that teachers are to be given "autonomy" in their development. In this regard, however, Hong Kong is quite lacking. Jin, Yeung, Tang and Low (2008) investigated the sources of stresses for Hong Kong high school teachers. The most common cited sources were high expectations of schools and parents. Interview studies also suggested that the dense reform syllabi led schools to 'compete' in training their teachers, exerting notable amount of stress (e.g., Chan, 1998; Tang, Au, Schwarzer \& Schmitz, 2001). In line with this, a recent study by Hargreaves and colleagues (2013) found that though Hong Kong teachers generally view collaborative learning positively, they reported lower levels of perceived autonomy (i.e., less inclination to think of their participation as voluntary) than the teachers from London. The results suggest a general trend of stakeholders pressuring teachers to engage in certain forms of teacher PD. As a result, the context in Hong Kong is that many (if not most) teachers do not have much autonomy over their PD, which can degenerate into a competition among schools in training teachers.

While teachers of Hong Kong are still mostly engaged in and committed to their careers in general (Choi \& Tang, 2009), there is an underlying worry of the long-term impacts of the teacher PD effort implemented by the Education Bureau. This is especially true considering that the negative effects of job stress on job commitment are often felt only over time (Lam, 2011, 2012), and the new teacher PD practices have been a relatively recent development in Hong Kong (Kennedy, 2005). Though the new measures implemented by the Hong Kong government seemed to have been reasonably well received, it does have its own underlying problems and worries.

\section{How Culture Shapes Hong Kong's Teacher PD}

Hong Kong is a Confucian Heritage Culture (CHC), whose values are shaped by the philosophy of Confucius (Penfold \& van der Veen, 2014). Based on our summary, the current trend of teacher PD practices in Hong Kong aligns with a pattern we expect from a CHC that tries to adopt western practices. As the Education Commission (2000) explicitly proposed: "our education system is infused with the essence of eastern and western cultures, preserving the basic elements of traditional Chinese education while absorbing the most advanced concepts, theories and experiences from modern western education" (p. 2); "Hong Kong's long term 
objective is not only to become one of the outstanding cities in China, but also a democratic and civilized international city embracing the cultural essence of the East and the West." (p. 28). This indicates the conscious effort to cater the teacher PD practices to Eastern culture and values. In CHCs, education systems are shaped by Confucian philosophy, whose influences on the behavior of teachers and students are widely known and studied (e.g., Nguyen, Terlouw \& Pilot, 2006). By analyzing how CHC has affected practices of teacher PD in Hong Kong, the current paper highlights that Hong Kong has placed emphasis on training workshops and courses and teachers' social networking in teacher PD. However, it may also have led to the more problematic aspects of Hong Kong's practices.

First, CHC would have explained why Hong Kong easily accepted the needs for training workshops and courses in teacher PD. At the core of such culture is Confucianism. The work of Confucian philosophers, 'The Three Character Classic', explicitly spells out its message: "It rewards one to work, but there is no reward to play". Traditionally, an ideal Confucian man is well-educated in philosophy and the humanities, much unlike an ideal western man, who is more akin to a knight; the ideal western man displays chivalry, courage, physical strength and wits (Li, 2003). Shaped by such an ideal, CHCs such as Hong Kong, China, Korea and Japan are well-known for having a strong obsession with academic pursuits, though frequently through rote-learning (Biggs, 1990, 1998). Therefore, it is not surprising that Hong Kong could easily comprehend the need to put forth teacher training workshops and courses in the promotion of teacher PD, as shown in the review. Indeed, in the statistics of the ACTEQ (2009b), teachers' responses suggested that they favored such learning. More than $90 \%$ of the teachers said that they found "structured learning" activities (such as workshops and courses) helpful for their PD, making these activities the most popular class among teacher PD activities provided by the Hong Kong government.

Another characteristic of $\mathrm{CHCs}$ is a general emphasis on social networks. Confucianism places importance on the 'Five Basic Relationships of Society' - a ruler and his subjects, fathers and sons, elder and younger brothers, husbands and wives, and friends. Confucius and his followers went through great lengths to work to promote the proper behaviors expected from these relationships. For example, the 'Book of Filial Piety', a very lengthy set of codes which Confucius derived to suggest how children should relate to their parents, proposes that while parents are obligated to protect and provide moral guidance for their young children, it is up to adult children to support their parents once the latter grow elderly. Similar works have been produced on the other four basic relationships. Hence, it is often said that the very foundation of each $\mathrm{CHC}$ lies in the relationships between individuals (e.g., Ip, 1996). Buddhism, another dominant philosophy among CHCs, also emphasizes the importance of relationships, albeit in a more metaphysical way. Buddhism taught that via pious practices (e.g., studies of scriptures and meditation), human beings can bring themselves closer to Enlightenment, which is necessary to reach Nirvana, a state of ultimate liberation from suffering and hence the noblest status a being can reach, according to Buddhist beliefs. A crucial stage before Enlightenment, however, 
is to become a Bodhisattva, a status where the being strives to help other beings on their way to reach Enlightenment. Even the Buddha himself, in Buddhist tradition, reckoned that he used to be a Bodhisattva before he attained True Enlightenment, and the worship of Bodhisattvas is a common practice of Buddhists who belongs to CHCs (Kariyawasam, 2002). Hence, there is little surprise that people of CHCs are reported to be more concerned about relationships than those from outside CHCs. People from CHCs are far more inclined to attend to relationships (Gold, Guthrie \& Wank, 2002), and to see themselves as members of groups instead of as individuals (Triandis, 2001). Hence, it is conceivable why Hong Kong, being a CHC, has used so many teacher PD practices related to social networking. The teacher Induction Scheme, Collaborative Lesson Planning, and mentorship programmes all have social network elements. Local teachers have also responded favorably to these practices, with over $70 \%$ stating that mentorship is helpful for their development (Lopez-Real \& Kwan, 2005). The survey of the ACTEQ (2006) suggested that $88 \%$ of the teachers in Hong Kong had engaged in peer lesson observations and $84 \%$ had participated in collegial collaboration like joint lesson preparation, reflecting high willingness to engage in practices oriented towards fostering relationships among teachers.

These elements of CHCs, however, have likely also contributed to the more problematic aspects of the teacher PD practices in Hong Kong. As one would expect from cultures that emphasize relationships, CHCs also tend to downplay or outright suppress the expressions of individuality (Triandis, 2001). As stated by Lam (2011):

The new demand for Hong Kong teachers to be involved in a process of enquiry - in a constructivist and learner-centered approach - has presented them with a major challenge as it is in conflict with the traditional role perception of teachers and students in Chinese classrooms, where teachers are authorities and students receive book knowledge passively. (p. 269)

This can explain why Hong Kong has ignored providing teachers with autonomy. While the latest trend of teacher PD practices encourages teachers to design their own professional development plans, teacher PD practices in Hong Kong have little (if any) of such elements. On the contrary, the measures the Education Bureau has implemented are mostly concerned with 'raising the standards' (e.g., requiring teachers to have certain qualifications or reach certain arbitrary performance criteria). Expectations from other stakeholders have also been reported to be the greatest source of stress for teachers in Hong Kong (Jin et al., 2008), supporting this idea. This is also likely a critical reason in Hong Kong's late adoption of the new approach to teacher PD, as compared to many parts of the globe. Despite not being especially backward, Hong Kong has not favored such practices as mentorship and collaborative learning until well into the early 2000s. By then, such practices were already normative in the Anglosphere (e.g., Villegas-Reimers, 2003). CHC's obsessions with 'raising the standards' may have made it more difficult to accept the notion about students' needs for non-academic development (and also, teachers' needs in this aspect). Hence, we suggest that many of the properties of teacher PD in Hong Kong can be partly attributed to its status as a CHC. 


\section{Lessons Learned from Hong Kong's Teacher PD Practices}

As a whole, Hong Kong has tried to adapt Anglosphere teacher PD practices to adhere to their new trends. However, it does not simply adopt every practice, but has instead been selective in choosing which measures to adopt. Namely, Hong Kong has deployed in-service trainings, teacher induction and school networking extensively, and local teachers responded to them favorably, especially teacher induction and school networking (Lopez-Real \& Kwan, 2005; Kwan \& Lopez-Real, 2005). In self-determination theory (Ryan \& Deci, 2000), relatedness could motivate humans to do a task out of the pleasure associated with it. When a warm, supportive figure is present during a certain task, humans experience a sense of security because the figure's presence signals availability of support (Deci \& Ryan, 2008). In turn, they would become more willing to take risk and learn through trial-and-error. This has been an empirically supported explanation for the motivation-enhancing effect of the presence of supportive others (Niemiec \& Ryan, 2009). Although this effect has been mostly demonstrated in the Anglosphere, it may be particularly crucial for members of CHCs.

This is because members of CHCs have been shown to be more in need of support and reassurance of others and conform to group opinions (Triandis, 2001), and hence may be more vulnerable to the negative effect of the absence of supportive others. Considering this, practices such as teacher induction and mentorship would be especially suitable for Hong Kong, and based on our reasoning, for CHCs in general. This suggests that when other CHCs (China, Taiwan, and Singapore) adapt teacher PD practices from the Anglosphere, they should consider focusing on practices based on social networking and inter-teacher relationships. On a broader scale, we suggest that different parts of the world should not blindly use practices demonstrated to be helpful in other countries, but should consider what motivates the people of their cultures. For instance, teachers in the USA and Australia may be more open to self-directed development compared to their counterparts in CHCs, because members of these cultures are far more inclined to need autonomy and self-assertions than to follow norms in making decisions (Rhee, Uleman, Lee, \& Roman, 1995).

Moreover, one phenomenon we have observed from Hong Kong is that the teacher PD practices have exerted stress on teachers primarily through the high expectations from various stakeholders and the anxiety that comes with it (Jin et al., 2008). This is explained via CHCs' tendency to emphasize "faces", and therefore fear looking incompetent (Thoma, McNaught, Wong, \& Li, 2011). In contrast, in the USA and Australia, teachers are more likely to report salary and promotion opportunities as their sources of stress (e.g., Zhai, Raver \& Li-Grining, 2011). This implies that when dealing with the problem of teacher stress, CHCs should consider approaches different from the ones used by the Anglosphere. A possible solution would be self-esteem training for teachers. One of the ways in which members of collectivistic cultures like CHCs diverge from their more individualistic counterparts (e.g., the Anglosphere) is that they, in general, tend to have lower self-esteem (Twenge \& Crocker, 2002). Self-esteem is essential for assuring an individual of his/her competence and thus, buffer against anxiety, the state in which a person experience 
negative emotions because of uncertainty about whether he/she could obtain what he/she wants. Also, a person with a high self-esteem also tends to be confident of his/her competence, thus more resilient against negative judgments (Kumpfer, 2002). Hence, self-esteem training can be of conceivably help to teachers in Hong Kong, and once again, probably teachers of CHCs in general. This point is important to remember as the Anglosphere is already taking actions to tackle the problem of high job stress reported among teachers (e.g., Collie, Shapka \& Perry, 2012). In this regard, we advise that it is not likely to be appropriate for CHCs to directly adapt the practices from the Anglosphere. Instead, they should derive their own practices in this regard, by catering to the needs of their own cultures.

\section{Concluding Remarks}

Currently, the Anglosphere is experiencing a trend in which teacher PD practices are to become more individualized and less focused on 'standard practices'. In response to this, the Hong Kong education system had adapted some of the new practices that were spawned from this trend. Specifically, they have adopted teacher induction, the establishment of social networks among teachers, and training local teachers in the required skills. The Hong Kong authorities, however, do not blindly adapt the practices from Anglosphere, but instead are explicit in their attempts to cater their measures to Eastern values and cultures. With this in mind, we identify how such values and cultures have influenced the teacher PD practices of Hong Kong and explained the teachers' responses to it. We identified a lack of self-direction as characteristic of teacher PD in Hong Kong, and discussed what education systems from other parts of the globe could learn from our analysis.

\section{References}

Advisory Committee on teacher Education and Qualifications. (2006). Task Force on Teachers' Continuing Professional Development. Hong Kong: Advisory Committee on teacher Education and Qualifications.

Advisory Committee on teacher Education and Qualifications. (2009a). Professional Development for Beginning teachers - An Induction Tool Kit (5th ed.). Hong Kong: Advisory Committee on teacher Education and Qualifications.

Advisory Committee on teacher Education and Qualifications. (2009b). Towards a Learning Profession: The teacher Competencies framework and the Continuing Professional Development of teachers. Hong Kong: Advisory Committee on teacher Education and Qualifications.

Avalos, B. (2011). Teacher professional development in Teaching and teacher Education over ten years. Teaching and teacher Education, 27(1), 10-20.

Ben-Peretz, M. (2011). Teacher knowledge: What is it? How do we uncover it? What are its implications for schooling?. Teaching and teacher Education, 27(1), 3-9.

Biggs, J. (1998). The assessment scene in Hong Kong. In P. Stimpson \& P. Morris (Eds.), Curriculum and Assessment for Hong Kong: One system, two components. (pp. 315- 324). Hong Kong: Open University of Hong Kong.

Biggs, J. B. (1990). Asian students' approaches to learning: implications for teaching overseas 
students. In Australasian Tertiary Learning Skills and Language Conference. Brisbane.

Bustingorry, S. O. (2008). Towards teachers' professional autonomy through action research. Educational Action Research, 16(3), 407-420.

Caprara, G. V., Barbaranelli, C., Steca, P., \& Malone, P. S. (2006). Teachers' self-efficacy beliefs as determinants of job satisfaction and students' academic achievement: A study at the school level. Journal of School Psychology, 44(6), 473-490.

Chan, D. W. (1998). Stress, coping strategies, and psychological distress among secondary school teachers in Hong Kong. American Educational Research Journal, 35(1), 145- 163.

Chan, E. (2002). Beyond pedagogy: Language and identity in post-colonial Hong Kong. British Journal of Sociology of Education, 23(2), 271-285.

Chan, S. (1999). The Chinese learner - a question of style. Education and Training, 41(6/7), 294-304.

Choi, P. L., \& Tang, S. Y. F. (2009). Teacher commitment trends: Cases of Hong Kong teachers from 1997 to 2007. Teaching and teacher Education, 25(5), 767-777.

Clarke, A. (1995). Professional development in practicum settings: reflective practice under scrutiny. Teacher and teacher Education, 11(3), 243-261.

Cobb, V. (1999). An International Comparison of teacher Education. ERIC Digest. Wash- ington, DC: ERIC Clearinghouse on Teaching and teacher Education.

Collie, R. J., Shapka, J. D., \& Perry, N. E. (2012). School climate and social-emotional learning: Predicting teacher stress, job satisfaction, and teaching efficacy. Journal of Educational Psychology, 104(4), 1189-1204.

Darling-Hammond, L., \& Richardson, N. (2009). Research Review/Teacher Learning: What Matters. Educational Leadership, 66(5), 46-53.

Day, C., \& Gu, Q. (2007). Variations in the conditions for teachers' professional learning and development: sustaining commitment and effectiveness over a career. Oxford Review of Education, 33(4), 423-443.

Deci, E. L., \& Ryan, R. M. (2008). Self-determination theory: A macrotheory of human motivation, development, and health. Canadian Psychology/Psychologie canadienne, 49(3), 182-185.

Education Bureau. (2010). Professional development - Primary teachers sharing seminar. (Chinese), Retrieved on Dec 24, 2014, from

Education Bureau. (2012). School-based Curriculum Development in the Primary Schools Collaborative Lesson Planning. Retrieved on Dec 24, 2014, from http://www.edb.gov.hk/en/edu-system/primary-secondary/applicable-to-primary-secondary/s bss/school-based-curriculum-primary/our-work/collaborative-lesson-planning/p1.html

Education Bureau. (2014a). Pamphlet on ACTEQ's teacher Induction Scheme. Retrieved on Dec 24, 2014, from:

Education Bureau. (2014b). School Support Partners (Seconded teacher) Scheme SSP. Retrieved on Dec 24, 2014, from

Education Bureau. (2014c). Teacher Training and Qualifications. Retrieved on Dec 24, 2014, from

Education Bureau. (2014d). Figures and Statistics: Primary Education. Retrieved on Dec 24, 2014, from http://www.edb.gov.hk/en/about-edb/publications-stat/figures/pri.html

Education Commission. (2000). Reform Proposal for the Education System in Hong Kong. Retrieved on Jan 6, 2014, from

Educational and Manpower Branch. (1993). School Education in Hong Kong: A Statement of Aims. 
Retrieved on Jan 6, 2014, from

Glatthorn, A. A. (1987). Cooperative Professional Development: Peer-Centered Options for teacher Growth. Educational Leadership, 45(3), 31-35.

Gold, T., Guthrie, D., \& Wank, D. (Eds.). (2002). Social connections in China: Institutions, culture, and the changing nature of guanxi (No. 21). Cambridge: Cambridge Univer- sity Press.

Guskey, T. R. (2002). Professional development and teacher change. Teachers and Teaching: Theory and Practice, 8(3), 381-391.

Hagger, H., McIntyre, D., \& Wilkin, M. (Eds.). (2013). Mentoring: perspectives on school- based teacher education. London: Routledge.

Hargreaves, E., Berry, R., Lai, Y. C., Leung, P., Scott, D., \& Stobart, G. (2013). Teachers' experiences of autonomy in Continuing Professional Development: teacher Learning Communities in London and Hong Kong. Teacher Development, 17(1), 19-34.

Hong Kong Government. (1978). The Development of Senior Secondary and Tertiary Education. Retrieved on Jan 14, 2014, from

Hong Kong Institute of Education. (2014). Programme information. Retrieved on Nov 20, 2014, from http://www.ied.edu.hk/acadprog/pdp/programme.htm

Hunter, A. B., Laursen, S. L., \& Seymour, E. (2007). Becoming a scientist: The role of undergraduate research in students' cognitive, personal, and professional development. Science Education, 91(1), 36-74.

Ip, P. K. (1996). Confucian Familial Collectivism and the Underdevelopment of the Civic Person. In N. K. Lo \& S. W. Man (Eds.), Research and Endeavors in Moral and Civic Education (pp. 39-58). Hong Kong: Chinese University Press.

Jin, P., Yeung, A. S., Tang, T. O., \& Low, R. (2008). Identifying teachers at risk in Hong Kong: Psychosomatic symptoms and sources of stress. Journal of Psychosomatic Research, 65(4), 357-362.

Kariyawasam, A. G. S. (2002). The Bodhisattva Concept. Kandy: Buddhist Publications Society.

Kennedy, K. J. (2005). Changing schools for changing times: New directions for the school curriculum in Hong Kong. Hong Kong: Chinese University Press.

Kumpfer, K. L. (2002). Factors and processes contributing to resilience. In M. D. Glantz \& J. L., Johnson (Eds.), Resilience and Development (pp. 179-224). US: Springer.

Kwan, T., \& Lopez-Real, F. (2005). Mentors' perceptions of their roles in mentoring student teachers. Asia-Pacific Journal of teacher Education, 33(3), 275-287. http://www.tandfonline.com/doi/pdf/10.1080/13598660500286267

Lam, B. H. (2011). A Reflective Account of a Pre-service Teacher's Effort to Implement Progressive Curriculum in Field Practice. Schools: Studies in Education, 8(1), 22-39.

Lam, B. H. (2011). Teachers as Researchers and teacher Development. In S. N. Phillipson \& B. H. Lam (Eds.), Learning and Teaching in the Chinese Classroom (pp. 265-290). Hong Kong: Hong Kong University Press.

Lam, B. H. (2012). Why do they want to become teachers? A Study on Prospective teachers' Motivation to Teach in Hong Kong. Asian Pacific Education Researcher, 21(2), 307-314.

Lam, B. H. (2014). Challenges beginning teachers face. Schools: Studies in Education, 11(1), $156-169$.

Li, J. (2003). The core of Confucian learning. American Psychologist, 58(2), 146-147.

Lopez-Real, F., \& Kwan, T. (2005). Mentors' perceptions of their own professional develop- ment 
during mentoring. Journal of Education for Teaching, 31(1), 15-24. http://www.tandfonline.com/doi/pdf/10.1080/02607470500043532

McKernan, J., \& McKernan, J. (2013). Curriculum action research: A handbook of methods and resources for the reflective practitioner ( 2 nd ed.). London: Routledge.

McLaughlin, M. W., \& Zarrow, J. (2001). Teachers engaged in evidence-based reform: Trajectories of teachers' inquiry, analysis, and action. In A. Lieberman \& L. Miller (Eds.), teachers caught in the action: Professional development that matters, Vol. 31 (pp. 79-101). New York: teachers College Press.

Neary, M. (2000). Supporting students' learning and professional development through the process of continuous assessment and mentorship. Nurse Education Today, 20(6), 463-474.

Nguyen, P. M., Terlouw, C., \& Pilot, A. (2006). Culturally appropriate pedagogy: the case of group learning in a Confucian Heritage Culture context. Intercultural Education, 17(1), 1-19.

Niemiec, C. P., \& Ryan, R. M. (2009). Autonomy, competence, and relatedness in the class- room: Applying self-determination theory to educational practice. Theory and Research in Education, 7(2), 133-144.

Penfold, P., \& van der Veen, R. (2014). Investigating Learning Approaches of Confucian Heritage Culture Students and teachers' Perspectives in Hong Kong. Journal of Teaching in Travel \& Tourism, 14(1), 69-86.

Rhee, E., Uleman, J. S., Lee, H. K., \& Roman, R. J. (1995). Spontaneous self-descriptions and ethnic identities in individualistic and collectivistic cultures. Journal of Personality and Social Psychology, 69(1), 142-152.

Ross, J. A., \& Bruce, C. D. (2007). Teacher self-assessment: A mechanism for facilitating professional growth. Teaching and teacher Education, 23(2), 146-159.

Ryan, R. M., \& Deci, E. L. (2000). Self-determination theory and the facilitation of intrinsic motivation, social development, and well-being. American Psychologist, 55(1), 68-78. http://citeseerx.ist.psu.edu/viewdoc/download?doi=10.1.1.335.6945\&rep=rep1\&type=pdf

Sandholtz, J. H. (2000). Interdisciplinary team teaching as a form of professional development. Teacher Education Quarterly, 27(3), 39-54.

Shulman, L. S. (1986). Those who understand: Knowledge growth in teaching. Educational Research, 15(2), 4-14.

Shulman, L. S. (1987). Knowledge and teaching: foundations of the new reform. Harvard Educational Review, 57(1), 1-22.

Speck, M., \& Knipe, C. (2005). Why can't we get it right? Designing high-quality profession-al development for standards-based schools. Thousand Oaks: Corwin Press.

Stringer, E. T. (2007). Action research (3rd ed.). California: Sage.

Tang, C. S. K., Au, W. T., Schwarzer, R., \& Schmitz, G. (2001). Mental health outcomes of job stress among Chinese teachers: role of stress resource factors and burnout. Journal of Organizational Behavior, 22(8), 887-901.

Thiessen, D. (2000). A skillful start to a teaching career: A matter of developing impactful behaviors, reflective practices, or professional knowledge?. International Journal of Educational Research, 33(5), 515-537.

Triandis, H. C. (2001). Individualism-collectivism and personality. Journal of Personality, 69(6), 907-924.

Twenge, J. M., \& Crocker, J. (2002). Race and self-esteem: Meta-analyses comparing whites, 
blacks, Hispanics, Asians, and American Indians and comment on Gray-Little and Hafdahl (2000). Psychological Bulletin, 128(3), 371-408.

Villegas-Reimers, E. (2003). Teacher professional development: an international review of the literature. Paris: International Institute for Educational Planning.

Visiting Panel. (1982). A Perspective on Education in Hong Kong. Report by a Visiting Panel. Retrieved from

Walling, B., \& Lewis, M. (2000). Development of professional identity among professional development school pre-service teachers: longitudinal and comparative analysis. Action in teacher Education, 22(2A), 65-72.

Wise, A. E. (2001). Creating a High-Quality Teaching Force. Educational Leadership, 58(4), $18-21$.

Zhai, F., Raver, C. C., \& Li-Grining, C. (2011). Classroom-based interventions and teachers' perceived job stressors and confidence: Evidence from a randomized trial in Head Start settings. Early Childhood Research Quarterly, 26(4), 442-452. 
Annex 1. Evolving Concepts and Enacted Activities of Teacher Professional Development in Hong Kong

The Early Period:

1980s and before

\section{The Recent Period:}

1990s
The Current Situation:

2000s and beyond

\begin{tabular}{|c|c|c|c|}
\hline & 1900 s allu weiore & $1990 \mathrm{~s}$ & zovos allu weyoma \\
\hline \multirow{2}{*}{ 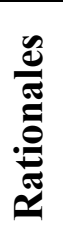 } & TEACHERS AS WORKERS & TEACHERS AS MULTI-TASKERS & TEACHERS AS LIFELONG LEARNERS \\
\hline & $\begin{array}{l}\text { Teacher PD is largely equated with } \\
\text { 'Initial and In-service training on subject } \\
\text { knowledge and pedagogies'. }\end{array}$ & $\begin{array}{l}\text { Teacher PD is regarded as 'Training on subject } \\
\text { knowledge, pedagogies, plus generic skills for } \\
\text { them to multi-task in schools'. }\end{array}$ & $\begin{array}{l}\text { Teacher PD is defined as 'Teachers' } \\
\text { self- directed lifelong learning in the } \\
\text { communities' by the ACTEQ. }\end{array}$ \\
\hline 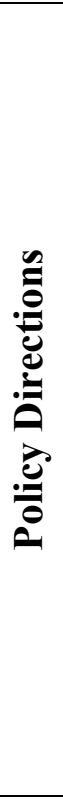 & $\begin{array}{l}\text { - "Account must also be taken of other } \\
\text { objectives, in particular ensuring a } \\
\text { regular supply of trained teachers to } \\
\text { meet teaching vacancies as they arise } \\
\text { and providing basic training for } \\
\text { untrained serving teachers." (Hong Kong } \\
\text { Government, 1978, p. 13) } \\
\text { "The lessons we observed tended to be } \\
\text { teacher-centred, with little use of aids } \\
\text { beyond chalk and blackboard." (Visiting } \\
\text { Panel, 1982, p. 51) "... Students spend } \\
\text { too little time in critical or analytical } \\
\text { thinking." (p. 55) "... The school system } \\
\text { should focus now on some of the } \\
\text { challenges caused by this rapid } \\
\text { enrolment build-up - the new issues } \\
\text { relate to quality rather than quantity." (p. } \\
\text { 56). }\end{array}$ & $\begin{array}{l}\text { - "Schools [...] should contribute to the personal } \\
\text { growth of their students, by helping them develop } \\
\text { a sense of morality and prepare for the physical, } \\
\text { emotional and mental transition to adulthood." } \\
\text { (Educational and Manpower Branch, 1993, p. 5) } \\
\text { "The recommendations (in that paper) mainly } \\
\text { focus on ways to improve school management and } \\
\text { performance towards the provision of quality } \\
\text { school education to better meet the needs of } \\
\text { students. [...] EC (Education Commission) finds } \\
\text { that there is a need to enhance the quality of the } \\
\text { present school system." (Education Commission, } \\
\text { 1997, p. 5) }\end{array}$ & $\begin{array}{l}\text { - “.. ACTEQ recommends that teacher } \\
\text { education institutions should be } \\
\text { constructed as learning communities } \\
\text { favourable to developing teachers" } \\
\text { capacity for lifelong learning. ACTEQ } \\
\text { also recommends an internship system } \\
\text { in order to provide new teachers with a } \\
\text { comprehensive environment conducive } \\
\text { to their development in } \\
\text { professionalism." (ACTEQ, 2003, p. i) } \\
\text { "COTAP will continue to champion the } \\
\text { robust development of our dedicated } \\
\text { teaching profession, a learning } \\
\text { profession ... quality and professional } \\
\text { teaching workforce will drive quality } \\
\text { education for the improvement of } \\
\text { student learning" (Committee on } \\
\text { Professional Development of Teachers } \\
\text { and Principals; COTAP, 2014) }\end{array}$ \\
\hline
\end{tabular}




\begin{tabular}{|c|c|c|c|c|}
\hline & 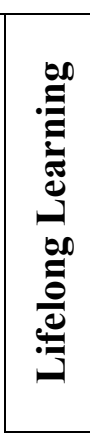 & N/A at this period & N/A at this period & $\begin{array}{ll}\text { - } & \text { The Generic Teacher Competencies } \\
\text { framework (2003) } \\
\text { - } \quad \text { The Teacher Induction Scheme (2005) } \\
\text { - Collaborative Lesson Planning, Peer } \\
\text { Lesson Observation and Exchange } \\
\text { programmes } \\
\text { - Sharing sessions within and outside } \\
\text { - Schools } \\
\text { Surveys on teachers' views on Teacher } \\
\text { PD practices }\end{array}$ \\
\hline 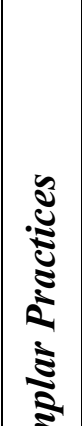 & 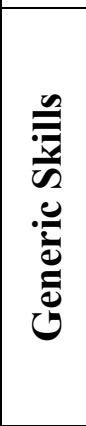 & N/A at this period & $\begin{array}{l}\text { - Setting up resource centers on specific topics: } \\
\text { The Guidance Teacher Resources Center in } \\
1995 \text {, which deals with counseling and } \\
\text { guidance for students } \\
\text { The Gifted Education Centre established in } \\
1995 \text { to cope with gifted education } \\
\text { - Information Technology Competence Levels to } \\
\text { develop teachers to be "able to use IT as } \\
\text { productivity tools to enhance the efficiency and } \\
\text { effectiveness of a teacher's work" (Au et al., 1999) }\end{array}$ & 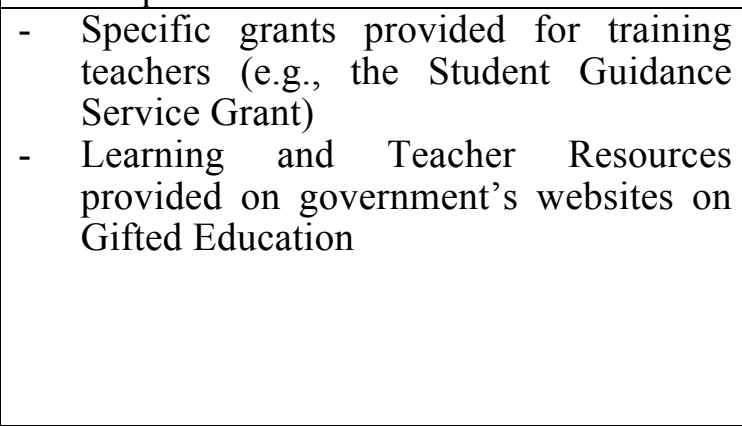 \\
\hline క్ & 占 & 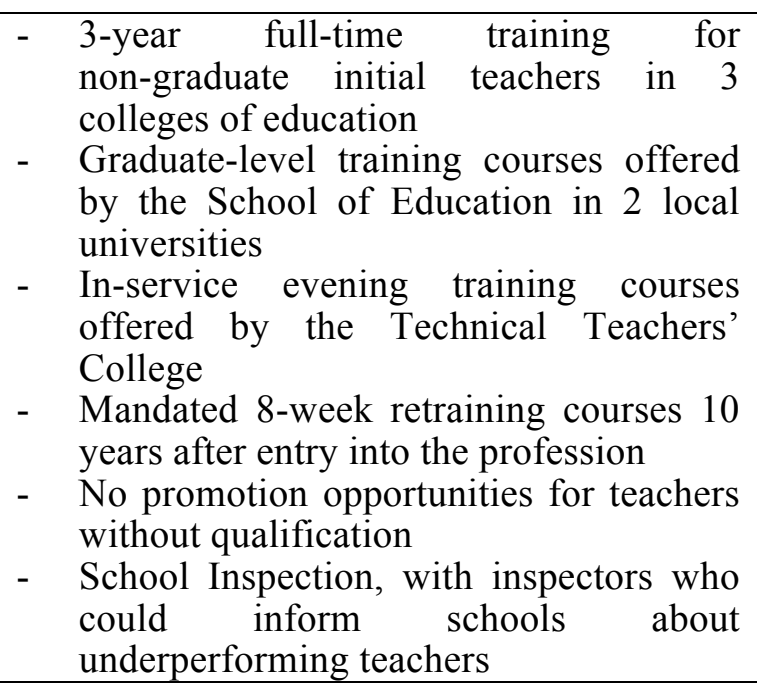 & $\begin{array}{l}\text { - Continuation of the previous requirements of } \\
\text { training and provision of courses } \\
\text { - Requirements that all teachers must be at least } \\
\text { trained graduates (1997) } \\
\text { - Number of places in teacher education at degree or } \\
\text { above level increased (1998) } \\
\text { - Full-time and part-time courses on counseling and } \\
\text { guidance offered to teachers by the major } \\
\text { universities } \\
\text { - Courses offered on specific competence } \\
\text { requirements and proficiency examination (e.g., IT } \\
\text { and language proficiency) }\end{array}$ & 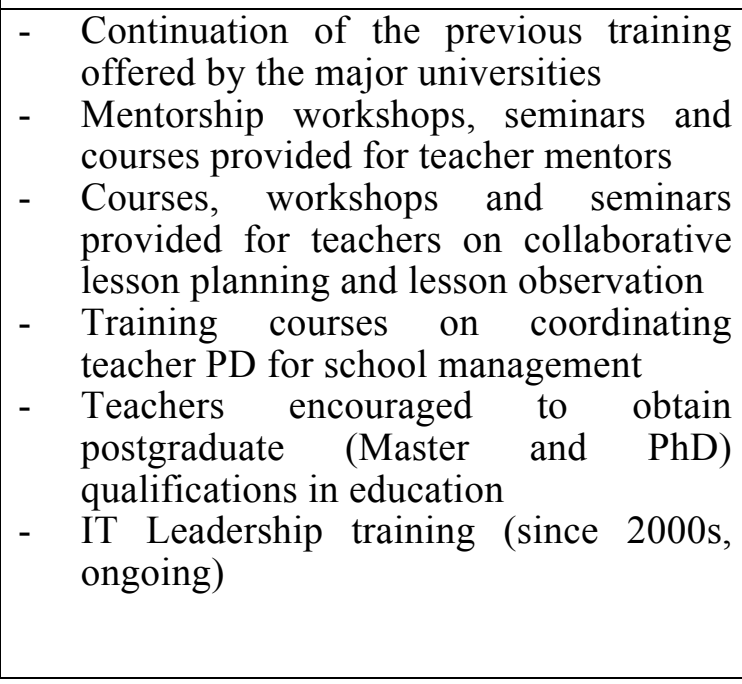 \\
\hline
\end{tabular}

